\title{
The Effectiveness of a Program Based on (NLP) in the Development of Social Communication for the Gifted Sixth Grade Students in Amman
}

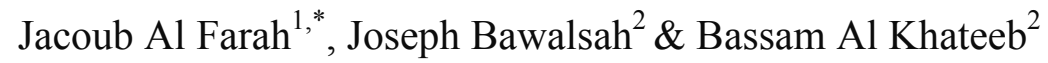 \\ ${ }^{1}$ Al Balqa Applied University, Salt, Jordan \\ ${ }^{2}$ Al-Ahliyya Amman University, Amman, Jordan \\ *Corresponding author: Al Balqa Applied University, Salt, Jordan
}

Received: October 29, 2015 Accepted: November 17, 2015 Published: March 25, 2016

doi:10.5296/ije.v8i1.9210 URL: http://dx.doi.org/10.5296/ije.v8i1.9210

\begin{abstract}
This study aimed to investigate the impact of a training program based on Neuro Linguistic Programming (NLP) in the development of social communications skills among gifted six grade students in the city of Amman. The sample of the study consisted of (60) gifted students from sixth grade for the second semester of the academic year (2012/2013). The students were divided into two groups, the experimental group with (30) students and the control group with (30) students. To achieve the objectives of the study a training program based on NLP was designed with ten training sessions. The measure of social communication was applied and was prepared by researchers from the perspective of NLP on the experimental and control group as pre and post measure. After an appropriate statistical analysis, the results showed statistically significant differences in social communication skills between the experimental group and control group in favor of the experimental group. Students in the experimental group showed better level of possessions and use of social communication skills. Depending on the results of the current study, the researchers have made a series of recommendations to take advantage of NLP in various fields of life.
\end{abstract}

Keywords: Neuro Linguistic Programming (NLP), social communications skills, gifted students 


\section{Introduction}

The importance of NLP appears to be with a strong technical help on personal development of the individual to the fullest extent (Obeid, 2006), it focuses on models that govern the way we live our lives. NLP corresponds with what an individual experienced in a world of rapid progress and change, and the primary task that we seek is the integration of the individual with his cognitive patterns to emulate with variables all around him, whether it was the self-ones or surrounding, to catch acceleration in the direction of development and humanitarian time (Al-Zahrani, 2005).

The NLP is a scientific method to bring about integration between the ways of human thinking, the construction of language plus internal sentimental forces and how to work on stimulating them to create the driving forces leading man permanently towards better change so that he becomes more committed, and able to endure responsibilities and frees himself from the impact of restricted thinking and previous cultures (Obaid 2006, Al-Sakka 2005, Helal 2004, Tou'ma\& Al-Athma 2003).

So, programming oneself is very important, where it is possible for human to re- program himself through identifying it first and then monitors the behaviors he wishes to avoid then finally acquire new habits and have it all through NLP (Saleh 2006).

\section{Neuro Linguistic Programming- NLP}

Most definitions of NLP focus on the personal development, as one of the means used by the individual to shift from unsatisfactory situations to better situations through innovating techniques that help to bring about positive change in people. The following is a review of the most important of these definitions:-

1- Grinder defines (Grinder, 2001) NLP as:A strategy for accelerated learning to discover and benefit from several styles and models in the world.

2- Al-Sakka (2005) defines it as: A collection of thoughts, feelings, behaviors, tools and techniques which combine with each other to develop human behavior.

3- Al-Takriti (2008) defines it as: An organized way to know the structure of the human self and deal with it with specific means and methods where they can influence decisively and quickly in the process of cognition and perception, ideas and feeling, and thus in behavior, skills and performance of human physical, intellectual and psychological in general.

4- Jensesn(Jensen, 2008)defines NLP as: A strategy used to teach people how to use their minds, and to do positive changes and give them the opportunity to change their lives, and also used for the formation of emotions and build positive habits and achieve liberation from internal conflicts.

This training program designed by researchers depended on a range of theories of NLP and the proponents of these theories emphasize that NLP provides ways and means applied to improve performance, and therefore, five skills in the designed training program had been 
adopted: (sensory language, representational systems, compatibility, standard and re-framing), in addition to hiring number of practical attitudes that are consistent with the NLP techniques.

The five criteria that have been studied (sensory language, representational systems, compatibility, standard and re-framing) can be illustrated as follows: (W.W.W.thabethejazi.com)

Sensory language: It is the language we use to describe what we see, hear, feel, smell and taste. It is a common fact and can be verified, and once you put an explanation for the sensory experience, you use language that is not based on senses. The aim of the sensory language is to develop the ability to note and not judge things randomly.

Representational system: It means the mechanism by which a person thinks and based on the five senses and show through movements of hands, the assertions of language, eye signals and the characteristics of each system, where each one of us has a representational system that dominate the rest of the systems. Types of representational systems are as follows:

1- The visual system: A person with a visual system has the following characteristics: talking quickly- has a high voice- interrupts the speaker very much- he takes decisions by what he sees- his breath is short and fast- depends on movements to support his words- is interested in pictures and landscapes- his stature upright- eats quickly- some of his linguistic expressions in the context of the speech: this idea is not clear to me/I see your point of view on the subject clearly/ this gives me a deep insight.

2- Audio system: A person with an audio system has the following characteristics: talking in a medium tone- listens without interrupting- prefers to refrain from talking - he takes decisions by what he hears and analyzes- breathing in a relaxed mannerbalanced movement- cares for voices- has a large rib cage- tone and degree of his voice varies-steadfast and straight with straight back- his linguistic expressions in the context of the speech: I hear you very well/ this is familiar to my ear/ I want you to her something with concentration.

3- Sensory system: A person with a sensory system has the following characteristics: Speaking slowly/ low voice/ he takes decisions by his feelings/ breathes slowly an deeply/ slow motion/ care for feelings and sensations/curved down back/ rounded shoulders/ his linguistic expressions in the context of the speech: I have strong feeling that you are right/ I feel you caught he tip of the thread/ the smell of this topic wafted/ I smell something improper in this matter.

Compatibility: Is the access to create an atmosphere of understanding and familiarity with the others, and that by focusing on understanding others and dealing with them in their own way without trying to change or judge them, some of compatibility steps are:

- Consistence: means symmetry with the other in movements, style of speech and breathing.

- Conformity: it means the repetition of consistency with the other. 
- Leadership: means to achieve the goal with the other in case he follows you.

Standard: It is observing expressive behavior and linking it to the internal situation of the individual. Standard is useful in: easy to communicate with others/improve marital relations/improve parenting relationship/increase flexibility.

Re-framing: It is the process of changing the frame a person sees the events through, and the basis of this process is the separation between intention and behavior, it is important to realize here that the meaning is in the context of the speech, if we change the context of the speech we change the original meaning. The process of re-framing goes through two main stages:

1. Develop a new framework for the meaning in the context: this process assumes that there is another meaning of behavior in the context of the speech, and when we put it in a new frame; we do not change in the context of the situation but $w$ change in the meaning.

2. Put the context in a new framework: This process assumes that there is another context for speech and behavior will have another positive meaning, and in this case the context of speech of the experiment will be formulated in another context.

\section{Pillars of NLP}

1. Outcome: It means identifying the target and the required intention of any act or behavior as an individual has to set his goal before starting any work where the techniques of NLP works to form and build emotional state toward the expected goal(Porter, 2002).

2. Flexibility: It means the willingness to change and modify i.e. whenever there are many options available to the individual result are better, and if what he does will not lead him to what he wants, he should follow another way, where NLP techniques work to encourage options for outcome, familiarity and compatibility with others (Almaadidi, 2005).

3. Positive initiative: It means to take the initiative with necessary steps, and the best for the person is to judge after trial and work (Andreas \& Andreas, 2005).

4. Raising the senses: It means the development of the power of observation and attention andthe optimal use of the senses, i.e. the collection of any information relating to the target and the desired behavior to be implemented more efficiently and better performance in the accuracy of observation (Farmawi, 2006).

\section{Presuppositions of NLP}

O'connor presented (Oconnor, 2004) a group of the most important underlying NLP assumptions, these assumptions are: 
1. The map is not the reality: the perception of people is subject to the self rather than a full description of the real and not necessarily reality, i.e. we see and respond according to our maps of the world which we acquire willingly.

2. Mind and body represent one system and people are working perfectly: there is a strong correlation between the mind and the body, the posture may express certain mood or perhaps an idea that may affect the development of the body, and to think that people are fully prepared to achieve certain results may not be the best in the surrounding circumstances, instead of thinking that humans have naturally extremes.

3. Experience has a structure and what is possible for me is possible for all: How we think about our experiences are subject to change, altering thinking change experiences, and what can be done by the person someone else is doing in light of the availability of all appropriate resources, and this assumption encourages to improve the performance beyond all limits they have set for themselves.

4. Human owns all needed resources: Everyone has a huge inventory of internal capabilities and talents, and the real achievement is as much as we recall what suits each position of the potential capabilities not to exceed external elements.

5. Realize that change can be cumulative: Because this allows the discovery of the amount of major cognitive changes or accomplishments that can be really achieved through few steps.

6. Behind every behavior positive purpose: There is always a purpose behind behavior, even if this behavior is negative, and this purpose is useful in dealing with others where it enables the individual to find out the reason behind such behavior, and discover their real needs, so as to find an alternative way to deal with them.

7. Fall into the wrong is not failure, but feedback: If the individual does not achieve his goal, it is worth looking at it as an experience for the future, rather than an evidence of the lack of ability to achieve what he wants to do.

8. Recognize that change can be cumulative: the change allows the discovery of the amount of major changes or accomplishments that can be really achieved through few steps.

\section{NLP properties and features:}

1. Integrated methodology: NLP adopts the idea that all parts and components of the individual interconnect with each other and must be viewed in an integrated manner, as any change in part reflects in the rest of the parts and affects it (Harris, 2004).

2. Minute details: NLP is interested in minute details, as studying details helps understanding, simulation and dealing with each element separately, rather than indulge in dealing with tangled activities at one time (Torubow, 2001).

3. Efficiencies and build role models: NLP is interested much in skills and individual capacities. Building models based on technology of NLP, especially with regard to 
the role models for active and distinguished people and work to identify elements of performance that contribute to their success, and thus help others to perform in the same manner to obtain the same results (Harris, 2004).

4. Mental processes: NLP directs great deal of attention to the impact of ideas on performance, and presenting several ways to modify mental patterns and mental images and correct ways to sequence these images and the strategic underpinning to help individuals make changes lead to the development of their lives, it does not focus on apparent behavior only (Grinder, 2001).

5. Linguistic patterns: NLP benefits from linguistic patterns in a way that allows effective techniques for interaction between the man himself and with others, to bring about the desired change; many of the processes of NLP are related to the language and patterns that are applicable in a variety of contexts (Harris, 2004).

6. Conscious and unconscious: NLP benefits from the influence of the unconscious at work through integration into the conscious so the effect will be more effective. Conscious is a state of awareness of the person for himself or for elements of the environment surrounding it, and the subconscious describes some of the mental processes that take place outside the framework of cognition such as sleeping and fainting and other (To'meh\&Alathmah 2003).

7. Execution speed and results: The modern thinking is based on the fact that the mind works and learns very quickly by focusing on the future, which is a characteristic that distinguishes NLP as a necessity for change (Robert, 2003).

Grinder (Grinder, 2001) pointed to a group of properties of NLP as follows:

Practical skills related to scientific base/ give and take from all sciences/ respect the privacy of each individual/ solve the problems and access to self-understanding and satisfaction/ easy to learn and does not require high specialization/ apply in all areas.

\section{Methods of NLP:}

1. Directed mental imagination: The ability to imagine or visualization is an important factor in the control of ideas that stand behind every emotion in order to facilitate the process of tuning and management of these emotions where the mental images which are formed in the individual, operates to reduce the psychological and physical exhaustion associated with emotions and it also weakens neural tendencies raised by grief (Al Zghoul\& Al Zghoul, 2003).

2. Packing mental: means to draw the attention of the individual deliberately to internal and external experiences which he is going through at this moment, with the aim of organizing and managing emotions through meditation, exercises and think, where this strategy is based on exercise the so-called reflection linear conscious, and packing mental operate to alleviate pain, stress, depression and anxiety, which encourages attention and awareness of his interior experiences, thoughts and emotions and also encourages him to pay 
attention to the environmental conditions associated with emotion such as sounds and sights (Khattab, 1981).

3. Modeling: although modeling and imitation are simple behaviors but they contain alert conscious that set the self of the individual for observation and imitation, and this focus of attention will be the accompanied by expectation of positive consequences on the acquisition and learning of the observed behavior, followed by the occurrence of retaining the symbolic representation of events, then imitation, where the whole direct the motivation of the learner to imitate the behavior (Harris, 2004).

4. Breathing exercises, relaxation and self-calm: these exercises work to disable most of the mental and physical energyresulting from negative emotion. The results of studies confirmed that conscious meditation caused by the exercise to the individual is what gives him the opportunity to think about his emotions consciously and yet exclude the idea of yielding to his negative emotions, where the individual begins to develop many alternatives that enables him to modify his mood and then choose the best, so that relaxation reduces our need for oxygen and a rapid heartbeat and thus alleviate biomechanical (friendly)and re-stimulate the nerve .system (unfriendly) (Jarrett, 2004).

5. Spiritual aspects: The principles that underpin NLP are basically humanitarian principle that communicate with the spiritual side of man, and is working to create a balance between mind and soul (Al-Zahrani, 2005).

\section{Importance of NLP}

Alder \& Heads (2003) see that the importance of NLP lies in:

1. Building good personal relations.

2. Taking positive mental direction.

3. Focusing on goals and employing energies to accomplish.

4. Feeling of trust towards any experience.

5. Strengthening self-esteem.

6. Finding ways and alternative solutions to the problems.

7. Taking advantage of the time efficiently.

8. Raising the level of performance.

\subsection{Statement of the study and its significance:}

The statement of the study is determined by investigating the impact of a training program for NLP in developing social communication skills among gifted students in the sixth grade in the city of Amman. The importance of the study lies in detecting the impact of NLP in social 
networking among students, and thus employs it in the development of social communication skills, it also provides educators with a theoretical background on the subject of NLP and its characteristics, and provides them also with a comprehensive training program for the development of communication skills based on NLP. This study is considered one of the first studies that examine the impact of NLP on social networking on a Jordanian sample.

\subsection{Questions of the study}

This study has sought to answer the following two questions:

First question: What are the skills of social networking available from the perspective of NLP with gifted students in the sixth grade in the city of Amman?

Second question: Are there any significant differences between the two groups (control and experimental) in term of the availability of social communications skills from the perspective of NLP with gifted students in the sixth grade in the city of Amman?

The importance of this study is in trying to answer these questions plus its attempt to verify the level of social communication skills possessed by gifted students and the extent of their ability to use these skills to understand their personal feeling and expressing it on one hand and to understand the feelings of others in social interactions on the other hand.

\subsection{Terms of the study}

Programming: It is what the people do according to their self-programs through programming the nerves system and the formation of an image to the outside world in mind (Sharab, 2004).

Linguistic: O'connor (Oconnor, 2004) sees that language includes verbal and non-verbal languages to communicate with others and self. The verbal language includes meanings and vocabularies owned by the individual, while non-verbal language includes body movements, nods, the way to sit or walk and stand, and the level of sound.

Neuro: Refers to the central nerves system i.e. the brain that controls functions of the body and its performance and activities as behavior, thinking and feeling and it receives information from us through the five senses (Obaid, 2006).

Gifted students: students of sixth grade, male and their academic achievement exceeds $90 \%$ and above in the first semester for the academic year 2012/2013.

Training program: it is a combination of overlapping areas of activities and interactions and experiences through which members of the group go as individuals and members of a group, and it is a mean not a target (Al Oteib, 1996). It is defined procedurally in this study as the training program designed by researchers and consists of series of training sessions organized chronologically and prepared theoretically according to the theories and techniques of NLP, where researchers manage those meetings in order to develop social networking among gifted students of the sixth grade in the city of Amman. 


\section{Previous studies}

There are many studies conducted on the NLP among students, we will present the most important of these studies as follows:

Al Sha'ar (2009) conducted a study aimed to investigate the impact of a training program based on NLP in the development of self-concept among a sample of gifted students of the tenth grade in Jordan. The sample consisted of (41) male and female gifted students and by (8) training sessions with (45) minutes for each. The results showed statically significant differences on the scale of self-concept in favor of the experimental group, the results showed also a lack of statistically significant differences for the variable gender.

Al Aljarmeh (2011) study aimed to investigate the effect of a training program based on NLP to improve social competence and the academic achievement. The sample of the study consisted of a group of male and female students with learning disabilities in Jordan. The results showed a clear improvement in social and academic achievement among students.

Al Mlmaadidi (2006) a study aimed to investigate the effect of a program based on NLP on the integration of cognitive patterns among students of the preparatory stage in Iraq. The sample of the study consisted of (60) male and female students, they were subject to (30) treatment sessions, and the results showed that NLP had a clear impact on the integration of cognitive styles and also the results showed no differences in the proportions of the variables gender and age.

Lavalle (2004) study aimed to prepare the individual and help him invest his abilities, and integrate him into the community through constructing an educational program based on the skills of NLP. The study was conducted on a sample of 120 students in the United States for period of (10) days with 5 training hours. The program included the following skills:

-Developing trends for the use of spontaneous models of thinking and behavior.

-To acquire and develop the skills of NLP and its application in practical life.

-Adjust the emotional status.

-The concept of time and the time line.

The results showed a positive change in some beliefs, and a change in the way of thinking, and an increase in adjusting emotional conditions, the results showed no differences for the variables gender and age.

Al Jaidi (2003) study aimed to implement a program based on NLP in the development of teaching and learning through strengthening the memory. The sample of the study consisted of (18) students from Saudi Arabia which lasted for a period of (21) training days. The results showed that the impact of the program was effective in strengthening the memory and consolidating information among students and the results showed no differences for the variables gender and age. 
Benny (2002) study aimed to increase self-confidence and increase the ability to take responsibilities plus getting rid of social phobia and all through a program based on NLP. The sample of the study consisted of (50) ordinary children in U.S.A, their age range between 8-12 years and by (18) sessions. The results showed that NLP has a significant impact in increasing self-confidence and the ability to take responsibility and get rid of social phobia, and also found no differences regarding the variable of age.

Kondalini (2002) study aimed to investigate the effect of representational patterns in NLP on education. The sample of the study consisted of (40) students in U.S.A through (15) training sessions. The results showed an improvement in education in terms of receiving information or answers to the questions and also the results showed no differences regarding the variable age.

Hardengham (1998) study aimed to determine the impact of NLP in improving the performance of classroom on a sample of (30) students in U.S.A and by (20) sessions. The results showed that NLP has an impact on improving the level of reading and improve the behavior of the learner and stimulate him plus increasing self-confidence and improve classroom communication, the result also showed no differences regarding the variable gender.

Helm (1989) study aimed to determine the impact of NLP on improving educational outcomes. The sample of the study consisted of (15) male and female students in U.S.A their age range between (12-16) years and through (20) training sessions. The results showed a clear improvement in learning outcomes among students and it increased their ability to learn and imagine the results also showed no differences regarding the variables age and gender.

Finally, Alexander (1979) study aimed to use the reframing technique in NLP to improve the processes of learning and cognition. The sample of the study consisted of (20) students in U.S.A and by (3) sessions per week for the period of (1) month. The results showed clear progress in the processes of learning and cognition, the results showed also no differences regarding the variable age.

\section{Methodology of the research}

The aim of this study is to investigate (the effectiveness of a training program based on NLP in the development of social communication skills among gifted students of the sixth grade in the city of Amman). This chapter presents a description of the members of the study, tools that have been built and used as its goal and how to respond to them and a mechanism to correct.

\subsection{Population and sample of the study}

The population of the study consisted of gifted students of the sixth grade in the city of Amman for the academic year 2012-2013. The sample of the study consisted of (60) gifted students who were randomly divided into two groups, control group (30) students and experimental group (30) students. 


\subsection{Methodology of the study}

The researcher used the quasi-experimental approach in this study and a suitable sample was selected. The sample of the study was divided randomly into two groups (control and experimental). After applying the social networking scale as a pre- test measure, the students of the experimental group underwent the experimental treatment which was the training program based on NLP. The training program was provided in the form of training sessions attended by these students. Then, the scale of social networking was applied as post-test measure to check the effect of the experimental treatment on the experimental group.

\subsection{Variables of the study}

3.3.1 The independent variable: the training program from the perspective of NLP for the development of social communications skills.

3.3.2 Dependent variable: social communication skills (sensory language, representational systems, compatibility, standard and reframing).

\subsection{Tools of the study}

The tools used in this study are:

1- The first tool: social networking measure.

2- The second tool: the training program based on NLP.

Below is a detailed overview of procedures for the construction and application of the two tools of the study:

\subsubsection{First: the social networking scale:}

The researchers developed the scale of the study, "social communication skills from the perspective of NLP ", and by reference to the literature of NLP and previous studies. The scale consisted of (35) items distributed on five areas (sensory language, representational systems, compatibility, standard and re-framing) as follows:

\section{Distribution of items of the scale on the five dimensions}

\begin{tabular}{llllllc}
\hline Areas & $\begin{array}{l}\text { Sensory } \\
\text { language }\end{array}$ & $\begin{array}{l}\text { Representational } \\
\text { systems }\end{array}$ & compatibility & standard & Re-framing & total \\
\hline $\begin{array}{l}\text { Sorting } \\
\text { paragraph }\end{array}$ & $1-5$ & $6-18$ & $24-19$ & $29-25$ & $35-30$ & 35 \\
$\begin{array}{l}\text { Number of } \\
\text { paragraphs }\end{array}$ & 13 & 6 & 5 & 6 & 35 \\
\hline
\end{tabular}

Answers on the items of the scale in "Likert" way and gradually quadrant as follows:

1-Always/ given 4 degrees 
2-Often/given 3 degrees

3-Sometimes/given 2 degrees

4-Rarely/given 1 degree

\subsubsection{Second: the training program}

\subsection{Definition of the program}

The program included a series of training sessions organized chronologically, and prepared theoretically prepared according to the theories and techniques of NLP, where the researchers manage those meetings in order to develop social communication among the gifted students of the sixth grade in the city of Amman. To build the training program they referred back to several sources:

- Review the theoretical literature on the subject and previous relevant studies.

- Access to several training programs designed for the development of social networking.

- Review the training programs based on NLP for the development of social networking.

Thus, the training program was constructed as follows:

1- Adopting the five social communication skills from the perspective of the NLP which has been rehearsed in the program (sensory language, representational systems, and compatibility, standard and re-framing).

2- Determine the number of sessions of (10 sessions) and the duration of each session is (45) minutes.

3- Identify a wide range of life situations, which represent the situations needed by the person during his social communication with others, these situations have been distributed on sessions in line with the five areas approved in the study.

4- A design had been set for the sessions of the training program so that the title of the session, the overall goal, private goal, the place of training will all appear through the design, and a classroom has been allocated for the training sessions of the program. Other titles will appear through the design such as: the type of training, the strategies which are used, the length of time, procedures the researchers carried out during training, tools and methods used in the training have been determined.

\subsection{The general goal of the program}

The goal of the program is mainly to develop the skills of social communication among members of the sample, and that by creating an interactive teaching and learning process done through training procedures based on the principles of NLP with members of the sample. 


\subsection{Methods of evaluation used in the program}

To evaluate the effectiveness of the benefit from the program and achieve its goals, the following actions are prepared:

- Conduct a pre-test on the experimental and control groups.

- Conduct a post-test after the completion of the application of the program to learn about the impact of the training program for members of the experimental group.

\subsection{Study design and statistical treatment}

To answer the questions of the research and to test the hypotheses contained therein, a Statistical Package for the Social Sciences and Humanities (SPSS) and adopted the following statistical methods:

1. Reliability test: Cronbach's Alpha was used to measure the reliability of the measurement tool.

2. The arithmetical means and standard deviations: the arithmetical means and standard deviations were extracted for each variable of the study variables.

3. Using t-test for one sample (One Sample T-Test).

4. Use test analysis of variance (One way ANOVA).

\subsection{Reliability test}

Cronbach's Alpah was used to measure the reliability of study tool according to the answers of the members of the study totaling (60) individuals, where the value of the Cronbach's Alpha for the area of sensory language $(\alpha=71 .$,$) and for the area of representational$ systems $(\alpha=85.6$.), compatibility ( $\alpha=62.2 .$,$) , standard (\alpha=73.1 .$,$) , re-framing (\alpha=66.1$.$) , the$ value of reliability to all areas of social communication skills $(\alpha=93.3$.), and this value is acceptable in researches and human studies for the purpose of achieving the goals of the study.

\section{Results}

The following is a presentation of the results of the key and sub-questions of the study, using descriptive and analytic statistical methods in processing data that emerged from the tool of the study, and then extracting the arithmetical means and the standard deviations in addition to $(\mathrm{T})$ value for a single sample as follows:

The first key question: What are the skills of social communication skills available from the perspective of NLP for gifted students in the sixth grade in the city of Amman?

To answer this question, it has been divided into five sub-questions searching in the availability of these skills among the members of the study in the following areas: 
(Sensory language, representational systems, compatibility, standard, re-framing) for each of the groups separately.

Table (1) shows the results related to the skills of social networking for members of the study from the perspective of NLP:

Table 1. The arithmetical means, standard deviations, $T$ value for social communication skills from the perspective of NLP

\begin{tabular}{lllllll}
\hline & \multicolumn{3}{l}{ Control group } & \multicolumn{3}{l}{ Experimental group } \\
\cline { 2 - 7 } & $\begin{array}{l}\text { Arithmetical } \\
\text { means }\end{array}$ & $\begin{array}{l}\text { standard } \\
\text { deviations }\end{array}$ & T-value & $\begin{array}{l}\text { Arithmetica } \\
\text { l means }\end{array}$ & $\begin{array}{l}\text { Standard } \\
\text { deviations }\end{array}$ & T-value \\
\hline $\begin{array}{l}\text { Sensory language } \\
\text { Representational }\end{array}$ & 1.84 & 0.39543 & -2.124 & 3.11 & 0.43844 & $13.908^{* *}$ \\
$\begin{array}{l}\text { systems } \\
\text { Compatibility }\end{array}$ & 1.94 & 0.34172 & -0.863 & 3.03 & 0.23187 & $24.530^{* *}$ \\
Standard & 2.13 & 0.38676 & 1.967 & 3.05 & 0.36919 & $15.577^{* *}$ \\
Re-framing & 1.95 & 0.49740 & -0.514 & 3.06 & 0.44048 & $13.264^{* *}$ \\
All areas & 2.11 & 0.35328 & 1.809 & 3.13 & 0.29712 & $20.994^{* *}$ \\
\hline
\end{tabular}

* Value statistically significant at the level $(\alpha=\leq 0.05)$

** Value statistically significant at the level $(\alpha=\leq 0.01)$

Table (1) shows that the social communications skills are not available for the students of the control group in all areas. The arithmetical means for the area (sensory language) (1.84), and the value of $\mathrm{T}$ value $(-2.12)$ which is negative and statistically insignificant. This means that communication through this skill was among students in the control group in the reverse direction. The area (representational systems) the value of the arithmetical means is (1.94) and the $\mathrm{T}$ value is (-0.86), which is negative value and also statistically insignificant. Moreover, the arithmetical means of the area (compatibility) (2.13) and the T value (1.96) which is positive value but statistically insignificant. The arithmetical means of the area (standard) has reached (1.95) and the value of $\mathrm{T}(-0.514)$ were statistically insignificant. The last area of social communication skills (re-framing) had the value of the arithmetical means (2.11), and the $\mathrm{T}$ value (1.809), a positive value but statistically insignificant. Finally, the arithmetical means for all areas of social communication skills for the control group (1.99) and the $\mathrm{T}$ value (-0.14), a negative value and statistically insignificant.

On the other hand, it appears from table (1) that the students of the experimental group and after applying the skills program on them, they show through their responses that they have developed all the skills of social communication in all area, as the arithmetical means for the area (sensory language) (3.11) and the T value (13.9) and this value is statistically significant. Moreover, the arithmetical means for the area (representational systems) (3.03) and the $\mathrm{T}$ value (24.53), a statistically significant value as well. In the area (compatibility) has reached the arithmetical means (3.05) and the T value (15.577) which is statistically significant. The 
means in the area (standard) (3.06) and the T value (13.26) which is statistically significant. Finally, the arithmetical means of the area (re-framing) (3.13) and the T value (20.9) and the valued is also statistically significant. The arithmetical means of all areas of social communication skills among students in the experimental group reached (3.07), and the $\mathrm{T}$ value (31.93) which are statistically significant at the significance level (0.01).

The second key question: is there a statistically significant difference between the two groups (control and experimental) in terms of the availability of social communication skills from the perspective of NLP for gifted students in the sixth grade in the city of Amman?

To answer this question the style of analysis of variance (one way ANOVA) was used to identify differences in the skills of social communication between members of the two groups (control and experimental). Table (2) shows the results that relate to the social communication skills of students in the sixth grade from the perspective of NLP:

Table 2. Analysis of variance test (one way ANOVA) to demonstrate the differences between the members of the control and experimental groups in social communications skills

\begin{tabular}{llll}
\hline Area & Group & $\begin{array}{l}\text { Arithmetical } \\
\text { means synthesis }\end{array}$ & T-value \\
\hline Sensory language & Control & 16.22 & $138.077^{* *}$ \\
& Experimental & 44.78 & \\
Representational systems & Control & 15.57 & $209.89^{* *}$ \\
& Experimental & 45.43 & \\
Compatibility & Control & 17.03 & $87.11^{* *}$ \\
& Experimental & 43.97 & \\
Standard & Control & 17.12 & $84.239^{* *}$ \\
& Experimental & 43.88 & \\
Re-framing & Control & 16.05 & \\
& Experimental & 44.95 & $507.112^{* *}$ \\
All areas & Control & 15.50 & \\
& Experimental & 45.50 & \\
\hline
\end{tabular}

*Value statistically significant at the level $(\alpha \leq 0.05)$

** Value statistically significant at the level $(\alpha \leq 0.01)$

Table (2) shows that there is a statistical significant differences between the members of the control group and experimental in all areas of social communication skills, with an arithmetical means of the synthesis of the area of sensory language, the two groups control and experimental (16.22) and (44.78), respectively, and the $T$ value (138.077) which is statistically significant at of the level of significance $(0.01)$, the area of representational systems the value of the arithmetical means of the synthesis for both control and experimental groups respectively (15.57) and (45.43), and the T value (209.89), which is also statistically significant. The arithmetical means of the synthesis for the area compatibility (17.03) and 
(43.97) for both control and experimental groups respectively, and the $\mathrm{T}$ value for the area (87.11) are statistically significant. As it turns out that the arithmetical means of the area standard for the control and experimental group respectively (17.12) and (43.88) and the T valued (84.239), which is statistically significant. As the area of re-framing,the value of arithmetical means for the control and experimental groups (16.05) and (44.95), respectively, and the $T$ value (147.112) which are statistically significant at the significance level (0.01). Finally, the value of the arithmetical means for the control and arithmetical groups for all areas of social communication skills among the students of the sixth grade (15.5) and (45.5), respectively and the $T$ value (507.263) which are statistically significant at the significance level (0.01).

Thus the previous results presented show that there are differences statistically significant at the level of significance $(0.01)$ between the control and experimental groups, where these differences were in favor of the experimental group, and this indicates the presence of the impact of the program based on NLP which has been applied to students of the experimental group, which the differences came in their favor.

\subsection{Discussion of the study}

We find from the results, there was a clear impact of the designed program based on NLP which has been applied to the experimental group and more clearly than it does with the control group. This means that the sensory language used by members of the experimental group to describe what they see, hear or feel and the ability to observe and judge realistically among the experimental group is better than the control group, and the results come in line with the results of previous studies (Ajarma 2011, Al Sha'ar 2009, Al Maadidi 2006, To'mah\& Al Athmah 2003).

As it turns out that the mechanism by which the experimental group thinks after the application of the come to rely on the five senses that appear through the movements of hands, assertive language, eye signals and the specific characteristics to each system whether (visual, auditory or sensory)and it is larger than the members of the control group. It also shows that there is an impact of the training program on the experimental group in making their ability to create an atmosphere on understanding and familiarity with others and deal with them in their own way without trying to change them or judging them, much more than the members of the control group.

It also shows that there is a positive impact of the training program to members of the experimental group in noticing the expressive behavior and linking it with the internal situation of the individual and easily communicate with others and flexibility, plus changing the frame in which the person sees events, and grasp the meaning in the context of the speech, and that more than the members of the control group.

This outcome have agreed with all previous studies in terms of the importance of the training program based on NLP to modify the behavior of the individual and the acquisition of new skills he did not possess earlier. The study also agreed with some of the studies in terms of the age of the sample (students in the elementary stage) such as the study of Helm(Helm, 
1989), and Benny(Benny, 2002), Al Sha'ar (2009), and also agreed with the study of Kondalini (Kondalini, 2002) and the study of Alexader (Alexander, 1979) in the nature of the sample being of the male students only, and agreed with Al Sha'ar(2009) who studied gifted students, but differed from the sudy Al Ajarmah (2011) who studied students with learning difficulties.

\subsection{Recommendations}

Depending on the results of the current study, the researchers offer the following recommendations:

1. The need to adopt NLP strategies as an essential component in the care programs for gifted students since these strategies have a positive effects in improving the standards of social communication among students.

2. Depending on the vocabulary of NLP strategies used in the current study as a training program and experimental treatment, the researchers recommend using these strategies as it provides alternative strategies for social communication based on the use of sensory language in describing audio and video stimuli, and the ability to note and judge.

3. Care programs of gifted students are based on group work in a lot of its parts, hence the use of NLP strategies will help to provide an atmosphere of intimacy and understanding between gifted students and others dealing with them, without trying to change their ideas and beliefs, which constitutes the basis of group work based on dialogue and cooperation.

4. In the absence of appropriate means to understand the emotional situation of self and others, providing students with NLP strategies contributes greatly to help these students to observe the expressive behavior of others and link it with the emotional situation of the person which facilitates the social contact with him, and the outcome ,to assist in the understanding of the framework the person see events through, and grasp the meaning in the context of the speech, and the separation between intentions and behavior.

5. Because of the limited sample of the study on males, the researchers recommended the need to conduct similar studies on samples from females and mixed group of male and female students to check the effects of NLP strategies on social communication between genders.

\section{References}

Al Sakka, Samer, (2005). And NLP and us, Saudi Arabia, Jeddah, Jarir Bookstore.

Al Zghoul, Rafi', \& Al Zghoul, Imad. (2003). Cognitive Psychology. Oman: Sunrise House.

Alajarmeh, Maysa. (2011). The effectiveness of NLP in improving social competence and 
academic achievement among students with learning disabilities in Jordan, Unpublished MA thesis, Amman Arab University, Amman.

Ald, Harry., \& Heads, Beryl. (2003). NLP in 21 days, (Translated by Jarir Bookstore) edition 1 Saudi Arabiak, Jarir Bookstore.

Al-Jeidi, saleh bin Said. (2003). The engineering program in the psychological development of learning and teaching through the strengthening of memory, network fort for Psychological Science and Humanities http//bafree.net.

Almaadidi, MaysaYahyaQasimm. (2006). The impact of the NLP in integration of cognitive patterns for students in preparatory stage MA thesis University of Mousel, Iraq.

Al-Otiebi, Alaa Shaker. (1996). Evaluation of educational program in representational activities in the development of self-concept amont high school students, Unpublished Ph.D. thesis, Faculty of Fine Arts University of Baghdad.

Al-Shaa'r, Anwar. (2009). The impact of a training program based on Neuro Linguistic Programming in the development of self-concept for gifted students in Jordan, Unpublished MA thesis, Balqa Applied University, Amman.

Al-Tikriti, Mohammed. (2008). Horizons without borders, $\left(4^{\text {th }}\right.$ ed.). Syria, Damascus, Horizon Without Borders Center.

Al-Zahrani Abed. (2005). Neuro Linguistic programming, volume 1, versions of the center of creative thinking, a series of books NLP (1), (edition1), Lebanon, Dar IbnHamza.

Andreas, Connera, \& Andreas, Steve. (2004). The heart of the mind "to take advantage of the change in your inner strength by using NLP" edition 1 (translated by Jarir Bookstore), Saudi Arabia, Jarir Bookstore.

Farmawi, Hamdi. (2006). Neuro psychology of language processing and communication disorders, Cairo, The Anglo-Egyptian.

Harris, Carol. (2004). NLP now easier $2^{\text {nd }}$ floor, Riyadh, Jarir Bookstore.

Hilal, Mohammad, (2004), Neuro Linguistic Programming "Effectiveness and communication with others, Egypt, the center of the development of performance and developments.

Jarat, Ted. (2004). NLP trainer effective, (Obeik translated versions) edtion 1 Giza, Cairo, the Professional expertise for management center, Obeik.

Khattab Al Arabi. (1981). published by the Center for Educational Development and Research, Yarmouk University, the role of the advisor teacher in self-concept and self-realization, volume, pp. 1-40.

Obeid, Ala. (2006). NLP edition 1 Amman, Dar Safaa'.

Porter, Lueso. (2002). Teacher's guide and the teacher and the family in the care of gifted students. Journal of Educational Sciences, Qatar, Qatar University, 1, 333-238. 
Saleh, Ibrahim. (2006). Cognitive Psychology (1st ed.). Oman: Dar Al Bedaya.

Tohe, Amal, Al Athmah, Rand. (2003). Engineering thinking for the development of thinking skills and intelligence based on kurtgobal program to expand the field of cognition, Jordan, Amman, the Al Hashemiah for printing.

Torbov, Brandon. (2001). Managers guide to deal with others. Riyadh, Jarir Bookstore.

\section{Copyright Disclaimer}

Copyright for this article is retained by the author(s), with first publication rights granted to the journal.

This is an open-access article distributed under the terms and conditions of the Creative Commons Attribution license (http://creativecommons.org/licenses/by/3.0/). 